\title{
Efeitos da Massoterapia sobre o Sistema Imunológico
}

\author{
Rosemeire de Jesus Carvalho ${ }^{1}$; Maria Antonieta Pereira Tigre Almeida ${ }^{2}$
}

\begin{abstract}
Resumo: A massoterapia pode ser definida como uma relação entre as técnicas tradicionais e contemporâneas, que embora não agrida o tecido muscular durante o seu manuseio, podem prevenir determinadas patologias, reestabilizando a saúde do indivíduo e resultando em bem-estar e numa melhor qualidade de vida. Este artigo teve como principal objetivo analisar a produção científica acerca dos efeitos da massoterapia no sistema imunológico, e utilizou-se de artigos e bibliografias do ano de 2001 até 2015. Onde foi realizada uma revisão sistemática da literatura, e seus artigos foram coletados da base de banco de dados: Google Acadêmico e SciELO, a partir dos descritores: massoterapia, sistema imunológico. A amostra foi empregada de dez trabalhos. As publicações analisadas descreveram as principais técnicas de massoterapia, bem como seus efeitos no organismo humano, destacando sua ação antinflamatória e consequentemente no sistema imunitário.
\end{abstract}

Palavras- chaves: massoterapia, sistema imunológico, saúde.

\section{Massotherapy Effects On The Immune System}

\begin{abstract}
Massotherapy can be defined as a relationship between traditional and contemporary techniques, which, although it does not attack the muscle tissue during its handling, can prevent certain pathologies, reestabilizing the health of the individual and resulting in well-being and better quality of life. This article had as main objective to analyze the scientific production about the effects of the massotherapy in the immunological system, and it was used articles and bibliographies from the year 2001 to 2015 . Where a systematic review of the literature was carried out, and its articles were collected from the base of database: Google Scholar and SciELO, from the descriptors: massage therapy, immune system. The sample was applied in ten studies. The publications analyzed described the main techniques of massage therapy, as well as its effects on the human body, highlighting its anti-inflammatory action and consequently the immune system.
\end{abstract}

Keywords: massage therapy, immune system, health.

\footnotetext{
${ }^{1}$ Acadêmica do Curso Superior de Estética e Cosmética da Faculdade Independente do Nordeste - FAINOR. Contato: rosemailcarvalho@gmail.com;

${ }^{2}$ Professora da Faculdade Independente do Nordeste - FAINOR, Intérprete de Libras, Bacharel em Letras-Libras pela Universidade Federal de Santa Catarina - UFSC, Mestre em Linguística pela Universidade Estadual do Sudoeste da Bahia UESB.
} 


\section{Introdução}

Define-se como massoterapia como um conjunto de técnicas tradicionais e contemporâneas, não invasivas, que visam prevenir determinadas patologias, buscando equilibrar a saúde do indivíduo, e tem como resultado o bem-estar e uma melhor qualidade de vida. É importante frisar que a massoterapia trabalha conjuntamente com a medicina tradicional, pois proporciona melhores resultados nos tratamentos oferecidos pela mesma. Seus objetivos principais são: além de prevenir doenças, melhorar a circulação e o tônus muscular, equilibrar as funções biológicas e assim remediar as dores, certas disfunções e ser excelente no alívio do estresse (DONATELLI, 2015).

Segundo mostram as descobertas arqueológicas onde havia desenhos que remetem a massagem corporal, ela foi instituída no Oriente Médio pelos povos egípcios e persas. Já no Ocidente, foram os gregos que difundiram esta prática, eles preservavam a boa aparência física, pois ela era sinônimo de beleza. Os romanos se massageavam em seus banhos públicos, pois acreditavam nos seus efeitos benéficos sobre o tecido muscular e em tratamentos de problemas de saúde (PEREZ et al., 2012, p.43-44). Dando continuidade, na China, a famosa Medicina Tradicional Chinesa teve seu inicio desde 2.800 a.C e depois foi difundida para a Coreia e o Japão, onde foram introduzidas as técnicas de acupuntura, usos das moxas e das ervas terapêuticas. Hoje elas têm grande influência sobre a atual massoterapia (DONATELLI, 2015).

No século 19, na Suécia, o Dr. Henry Pahr Ling uniu a massagem à terapia médica ocidental e a denominou de "massagem clássica". A massagem ocidental tem como fundamentos básicos: a recuperação dos sistemas muscular, articular e ósseo, o manejo do sistema circulatório e do transporte do sistema linfático além da atuação nas práticas esportivas. Seguindo esta linha, no século 20 , a descoberta da interação do corpo físico com a mente fez com que estas técnicas fossem aperfeiçoadas, dessa vez foi introduzido o apalpamento do conjunto esponjoso, trabalhando no sistema nervoso e em seus movimentos (PEREZ et al., 2012, p.45-46). Na Índia, também no século 20, o obstetra Frédérick Leboyer, desenvolveu uma massagem para bebês, que recebeu o nome de Shantala (DONATELLI, 2015).

As técnicas foram se aprimorando e hoje em dia, o toque é usado em diversos tipos de massagem, sendo as mais utilizadas: massagem chinesa, massagem tailandesa, massagem indiana, massagem craniossacral, massagem desportiva, massagem para reabilitação, 
massagem relaxante, drenagem linfática, o shiatsu, a Reeducação Postural Global (RPG) e o Reiki (DONATELLI, 2015).

\section{Objetivos}

Este artigo tem como objetivo principal sistematizar com base na literatura os efeitos da massoterapia no sistema imunológico, pois de acordo com Donatelli (2015), a massagem no tecido muscular tem a finalidade de abastecer as células através do sangue, promover a organização das atividades do tecido conjuntivo e dos fibroblastos além de ter propriedades anti-inflamatórias. De tal forma, pretende-se confrontar outras publicações sobre, se a aplicação das técnicas de massagem podem influenciar no sistema imunológico, fazendo com que o leitor desenvolva a capacidade crítica e argumentativa deste objeto de estudo científico e o favoreça nas suas próprias conclusões.

\section{Justificativa}

A revisão sistemática é considerada uma relação entre determinadas afirmações cientificas de alguns estudos, buscando dar resposta à questão única da pesquisa. Para isso, emprega se o uso da revisão literária, que apesar de ser um processo neutro, também é extenso e copiável. Logo após ser encontrado, avaliado e resumido, dele se extrai uma visão mais ampla e fiel daquilo de que se é esperado, também como seu efeito irá interferir naquela situação (BRASIL, 2012, p.13).

O intuito deste trabalho acadêmico é propor um estudo que avalie uma possível influência das técnicas de massoterapia sobre o sistema imunológico humano. Os efeitos da massagem vão muito além das funções relaxativas, elas são comprovadamente curativas. Sabese também da importância do bom funcionamento do sistema imunológico e das consequências negativas de uma possível falha desse importante mecanismo de defesa do nosso corpo. Os estudos decorrentes desta pesquisa têm como intuito produzir uma documentação sistemática, atando todos os fatores que indiquem a influência direta e/ou indireta da massoterapia no sistema imunológico e constituindo-se dessa maneira como uma contribuição para o meio 
científico, como também para sua popularização, visto que se comprovado seus benefícios mais estudos surgirão sobre este tema e mais ciência por parte das pessoas.

\section{Metodologia}

Foi realizada uma revisão bibliográfica sistemática e descritiva, através de uma pesquisa rigorosa de artigos científicos, obtidos em sites acadêmicos como: o Scielo e Google Acadêmico e também em livros. Foram utilizadas as seguintes palavras-chaves: massoterapia, sistema imunológico e saúde. Como critérios de inclusão foram utilizados artigos cuja temática abordasse o tema proposto e por meio de palavras chave encontradas nos títulos e resumos e, bem como obras que foram publicados do ano de 2012 a 2015.

Como critérios de exclusão foram retirados estudos que não se enquadram no período. Após a averiguação destes dados, foi realizada uma leitura para checar se havia a possibilidade de sua afinidade com o tema. A revisão sistemática bibliográfica usa como critério a Metanálise, sendo ela uma probabilidade estatística que reúne vários resultados de estudos diferentes, transformando-os em uma única avaliação de efeito sobre determinado tema. Ela apresenta um cálculo aproximado indispensável para a pesquisa, indicando qual o grau de efeito da intervenção que muitas vezes com um único estudo não conseguiu satisfazer as expectativas, seja por metodologia não adequada ou a população de estudo escassa (BRASIL, 2012, p.13).

\section{Resultados e Discussões}

Conforme quadro apresentado abaixo, esta pesquisa bibliográfica acatou dez artigos científicos, pois eles se enquadraram aos critérios de inclusão e serão discutidos no decorrer deste trabalho. 


\begin{tabular}{|c|c|c|c|c|c|c|c|}
\hline $\mathbf{N}^{\circ}$ & Título do Artigo & Autor & $\begin{array}{l}\text { Ano } \\
\text { de } \\
\text { Públi- } \\
\text { cação }\end{array}$ & Categoria & Suporte & $\begin{array}{c}\text { Tipo } \\
\text { da } \\
\text { Pesquisa }\end{array}$ & Objetivos \\
\hline 1 & $\begin{array}{l}\text { Ayurveda: a ciência da auto } \\
\text { cura: Guia Prático }\end{array}$ & LAD & 2012 & Livro & $\begin{array}{l}\text { Editora } \\
\text { Ground }\end{array}$ & Bibliografia & $\begin{array}{l}\text { Apresenta um guia } \\
\text { da massagem } \\
\text { ayurvédica, bem } \\
\text { como seus } \\
\text { benefícios. }\end{array}$ \\
\hline 2 & $\begin{array}{l}\text { Massagem Ayurvédica: } \\
\text { Ciência da Vitalidade }\end{array}$ & CARDIM & 2012 & Livro & $\begin{array}{l}\text { Editora } \\
\text { Dinalivro }\end{array}$ & Bibliografia & $\begin{array}{l}\text { Fala dos benefícios } \\
\text { da massoterapia para } \\
\text { todo o corpo, } \\
\text { focando na } \\
\text { massagem } \\
\text { ayurvédica. }\end{array}$ \\
\hline 3 & $\begin{array}{l}\text { Manual Técnico de Estética: } \\
\text { Teoria e prática para Estética, } \\
\text { Cosmetologia e Massagem }\end{array}$ & $\begin{array}{l}\text { GONÇALVE } \\
\mathrm{S}\end{array}$ & 2006 & Livro & $\begin{array}{l}\text { Editora } \\
\text { Ondagrafe }\end{array}$ & Bibliografia & $\begin{array}{l}\text { Apresenta um } \\
\text { manual de } \\
\text { procedimentos } \\
\text { estéticos, entre eles } \\
\text { de massagens. }\end{array}$ \\
\hline 4 & $\begin{array}{l}\text { Manual de Massagem } \\
\text { Terapêutica }\end{array}$ & CASSAR & 2001 & Livro & $\begin{array}{l}\text { Editora } \\
\text { Manole }\end{array}$ & Bibliografia & $\begin{array}{l}\text { Descreve as técnicas } \\
\text { da massagem bem } \\
\text { como suas aplicações } \\
\text { nas mais variadas } \\
\text { patologias* }\end{array}$ \\
\hline 6 & $\begin{array}{l}\text { Diretrizes metodológicas: } \\
\text { elaboração de revisão } \\
\text { sistemática e metanálise de } \\
\text { ensaios clínicos randomizados }\end{array}$ & BRASIL & 2012 & $\begin{array}{l}\text { Manual } \\
\text { técnico }\end{array}$ & $\begin{array}{l}\text { Editora do } \\
\text { Ministério da } \\
\text { Saúde }\end{array}$ & Bibliografia & $\begin{array}{l}\text { Falar sobre a } \\
\text { importância da } \\
\text { revisão sistemática }\end{array}$ \\
\hline 7 & $\begin{array}{l}\text { Massage therapy attenuates } \\
\text { inflammatory signaling after } \\
\text { exercise-induced muscle } \\
\text { damage }\end{array}$ & CRANE et.al & 2012 & artigo & $\begin{array}{l}\text { Science } \\
\text { Translational } \\
\text { Medicine }\end{array}$ & Bibliografia & $\begin{array}{l}\text { Relata os efeitos } \\
\text { positivos da } \\
\text { massagem no corpo } \\
\text { humano à nível } \\
\text { celular }\end{array}$ \\
\hline 8 & $\begin{array}{l}\text { A linguagem do toque: } \\
\text { massoterapia oriental e } \\
\text { ocidental }\end{array}$ & $\begin{array}{l}\text { DONATELL } \\
\text { I }\end{array}$ & 2015 & livro & Editora Roca & Bibliografia & $\begin{array}{l}\text { Falar sobre a } \\
\text { massoterapia e suas } \\
\text { técnicas bem como } \\
\text { sua atuação no } \\
\text { sistema imunológico }\end{array}$ \\
\hline 9 & $\begin{array}{l}\text { Técnicas de massagens } \\
\text { ocidental e oriental }\end{array}$ & PEREZ et.al & 2014 & livro & Editora Érica & Bibliografia & $\begin{array}{l}\text { Fala sobre a } \\
\text { importância da } \\
\text { massagem e seus } \\
\text { benefícios }\end{array}$ \\
\hline 10 & $\begin{array}{l}\text { Protocolos } \\
\text { Terapêuticos de } \\
\text { Massoterapia }\end{array}$ & VERSAGI & 2015 & Livro & $\begin{array}{l}\text { Editora } \\
\text { Manole }\end{array}$ & Bibliografia & $\begin{array}{l}\text { Orienta sobre as } \\
\text { práticas terapêuticas } \\
\text { e seus benefícios } \\
\text { para o sangue e } \\
\text { sistema imunitário }\end{array}$ \\
\hline
\end{tabular}

Quadro 1 - Artigos que se enquadraram nos critérios de inclusão. 
Antes de se iniciar qualquer método terapêutico, deve se antes realizar uma anamnese bem detalhada, pois ela tem a finalidade de colher dados importantes sobre o paciente, que podem auxiliar no tratamento, bem como traçar o melhor tratamento para cada caso e prevenir desastres. E por vezes é nela que se descobre a necessidade de uma equipe multidisciplinar, visto que o massoterapeuta não realiza diagnósticos. Por questões éticas, só o profissional deve ter acesso a esse documento (CASSAR, 2001, p.32-33).

O toque apazigua os sentimentos e afetos, pois ele é um tipo de cuidado onde se libera substâncias neuroquímicas como endorfina e serotonina, desencadeando numa profunda sensação de prazer. Quando feito por alguém em que confiamos, ele nos promove o autoconhecimento (PEREIRA, 2013, p.66)

A habilidade de palpar a pele como um todo, deve ser exercitada pelo profissional massoterapeuta, pois além de desenvolver a capacidade do toque sensorial, o profissional pode identificar possíveis lesões ou falhas nos tecidos, tais como: verrugas de formatos irregulares, psoríase, herpes-zoster, perda de elasticidade e outras disfunções da pele, a pressão sobre o local deve ser cautelosa, ainda que a mesma esteja hidratada. Ela deve estar livre de qualquer cosmético (CASSAR, 2001, p.43-46).

São muitos os escritos que mostram a influência das emoções e da cultura na sensação da dor. O humor, a autoestima e necessidade de ser amado juntamente com a saúde em desequilíbrio altera a forma com que as pessoas percebem a dor física e psicológica. Segundo estudos científicos, já se foi comprovado que a dor crônica leva a irritação e a depressão. A contínua interação destes fatores estressantes gera a "tríade terrível", que são o sofrimento, a insônia e a tristeza. Neste sentido o massoterapeuta deve ter uma visão holística sobre o indivíduo a ser tratado, usando de todos os artifícios disponíveis como profissional para tratar seu paciente em níveis: corporal, mental e espiritual (VERSAGI, 2015, p.29-30).

Em seu livro, Cardim (2012), descreve os atributos da massoterapia para o organismo humano, porém focando na massagem ayurvédica. Ela é muito eficaz no tratamento do estresse, pois uma vez que ela atua nos tecidos consegue oxigená-los de forma eficiente, devolvendo seus nutrientes e reparando o cansaço. Este processo vai se dando aos poucos na medida em que as veias e a linfa vão trabalhando normalmente. Além disso, quando há a liberação das toxinas, consequentemente se vê a melhora na circulação sanguínea que promove melhora do quadro de ansiedade e também atua nos fatores do rejuvenescimento. 
Este outro autor confirma que a massagem promove através da manipulação dos edemas corporais, a evacuação das toxinas através da urina e das fezes, atua no aumento de sangue circulante local, liberando as células gordurosas. A técnica da drenagem linfática pode ser feita mesmo que os vasos linfáticos profundos estejam danificados, basta drenar os vasos superficiais não impedindo a circulação da linfa (DONATELLI, 2015).

Podemos encontrar em Versagi (2015, p.11), a importância do sangue para a manutenção da vida ao dizer que ele é um líquido muito precioso, pois em desequilíbrio compromete inteiramente a saúde, causando um processo inflamatório nos tecidos o qual leva a dor e a doença, dessa forma o massoterapeuta trabalha bastante para que haja uma boa circulação nas áreas de muita tensão. Quando há o aumento do sangue circulante, há o desencadeamento de outros mecanismos biológicos, sendo eles: eliminação de toxinas, a termorregulação, ativação das células de defesa, normalização das atividades hormonais, células oxigenadas e consequentemente a renovação e a atividade normal de todos os tecidos e órgãos.

Na medida em que o individuo vai sendo beneficiado pela massagem, seu corpo começa a mostrar resultados positivos: como diminuição da fadiga, relaxamento dos nervos, diminuição da agitação mental, melhora da flexibilidade e da coordenação motora, combatendo a insônia e auxiliando no processo de regeneração celular resultando na melhora do aspecto da cútis. Após a massagem ayurvédica é devolvido ao paciente a sensação de tranquilidade, leveza e vigor (CARDIM, 2012).

Há alguns fatores que influenciam diretamente na massagem são eles: a direção do movimento, a intensidade da pressão, a frequência e o ritmo dos movimentos, os meios a ser utilizada, a posição correta, como também a duração e a frequência do tratamento (GONÇALVES, 2006, p.126).

\section{Direção}

Conforme o que diz na literatura, até que a massagem não fosse estudada por Hipócrates, acreditava-se que a direção da massagem era centrífuga. Desde então se descobriu que seu movimento era centrípeto. Isso contribuiu muito para que ela fosse introduzida nos tratamentos médicos e acabou por influenciar outros estudiosos no século XIX, como Ling que defendeu a 
tese de que os deslizamentos leves deveriam ser feitos na direção centrífuga e os movimentos de pressão mais densa na direção centrípeta. Já, Mennell disse que os movimentos profundos deviam ser centrípetos, pois eles iriam auxiliar no bom funcionamento dos sistemas venoso e linfático (GONÇALVES, 2006, p.126).

\section{Pressão}

O movimento de pressionar deve ser firme, porém não doloroso (GONÇALVES, 2006, p.126).

\section{Frequência e Ritmo}

Quando se fala da frequência dos movimentos de massagem, é importante frisar sobre o ritmo no movimento de deslizamento, pois eles devem ser lentos, leves e rítmicos, bem como ter o mesmo intervalo quando se começar e terminar cada movimento. Isso deve ser levado em conta para que os estímulos gerados pela técnica possam surgir os efeitos esperados (GONÇALVES, 2006, p.126- 127).

\section{Meios}

Para que ajam melhores resultados da massagem, Lad (2012) recomenda que sejam utilizados durante este procedimento os óleos vegetais, uma vez que através de sua propriedade em dispersar o calor uniformemente na epiderme, eles têm o poder de retenção hídrica na pele por meio de seus vários componentes entre eles: os hidratos de carbono e as proteínas promovendo por meio destes mecanismos a hidratação e atuando assim no combate ao envelhecimento precoce. $\mathrm{O}$ óleo a ser utilizado na massagem deve ter $\mathrm{pH}$ neutro, sem cheiro e sem substancias químicas. Faz se necessário espalhar na palma das palmas e depois desliza-las por todo o corpo.

\section{Posição correta}

A partir do século XX, após a descoberta da lei da gravidade, começou a ser notada a importância do paciente se sentar numa maca em posição confortável, pois assim se é 
favorecido o relaxamento total do corpo, facilitando a circulação venosa e linfática (GONÇALVES, 2006, p.127).

\section{Duração}

A duração do tratamento depende além das condições físicas do paciente e/ou também do efeito esperado (GONÇALVES, 2006, p.127).

Frequência

Até hoje de que se tem conhecimento, todos os autores concordam que a massagem deve ser contínua não só no tratamento, mas também para manutenção do quadro saudável (GONÇALVES, 2006, p.127).

\section{Manobras de massagem}

Para Gonçalves (2006, p.131) elas são divididas em sete grupos, cada uma possui uma função e apesar de cada manobra poder ser repetida, elas podem e devem ser combinadas no mesmo tratamento.

\section{Deslizamento}

Gonçalves (2006, p.131-132), diz que ela deve ser utilizada ao iniciar a massagem e consiste num deslizamento suave da palma das mãos ou dos dedos e com pressão precisa e movimentos rítmicos, suaves e repetitivos (sugere-se no mínimo sete vezes para todos os movimentos). Ela produz efeito calmante uma vez que age nos sistema linfático e venoso superficial, permite a liberação de hormônios e de outras substâncias neurotransmissoras, levando ao relaxamento e, portanto há a diminuição da dor, da tristeza e da ansiedade. No ato do Deslizamento, ocorre o aumento da grande circulação, influenciando o trabalho do sistema linfático na redução de edemas, fortificando o sistema imunológico, ativando as trocas hormonais, melhorando a circulação local e o tônus muscular. Há também o aumento da pressão arterial e dos batimentos cardíacos e em seguida a estabilização dos mesmos (VERSAGI, 2015, p.11).

\section{Pressões}

Conhecida como massagem de pressões por pontos, sua manipulação é local, porém de efeito profundo. Sendo assim se considera: baixa pressão, age em nível superficial (de 30-50 
mmHg), pressão média (50-80 mmHg) e pressão alta, age em nível venoso profundo e muscular (80 $\mathrm{mmHg})$. Seu efeito é estimular a corrente sanguínea dos tecidos em geral, por este motivo é uma técnica contraindicada para pacientes hipertensos (GONÇALVES, 2006, p.132).

\section{Amassamentos}

Com os nós dos dedos faz se o movimento de arraste, girando-o no local. Age profundamente nos tecidos musculares, induzindo ao aumento do metabolismo e consequentemente na eliminação de células gordurosas e retenção hídrica, devolvendo assim a vitalidade dos tecidos. Eles devem ser rítmicos, profundos e repetitivos (GONÇALVES, 2006, p.132-133). Quanto ao Amassamento por compressão, Versagi (2015, p.11), confirma que quando ela é executada: há a liberação das toxinas do tecido, alívio do enrijecimento dos músculos, alívio da dor, melhor desenvoltura dos movimentos corporais, melhor flexibilidade do tecido conjuntivo e aquecimento do tecido trabalhado.

\section{Fricções}

Esta outra técnica chamada de Fricção transversa profunda utiliza a liberação miofascial, a fim de evitar um processo inflamatório originado por uma lesão, cirurgia ou sedentarismo, e age significativamente no processo de cicatrização por meio do aumento da circulação local, da estimulação das fibras de colágeno que sofrem uma inflamação e imediatamente se regeneram e acabam por atuar no preenchimento dos sulcos. Atua também na supressão da dor e na redução da rigidez muscular (VERSAGI, 2015, p.19). O movimento é executado numa só direção, num trajeto de ida e vinda ou circulatório, sendo rítmicos, coordenados e localizados (GONÇALVES, 2006, p.133).

\section{Percussões}

Esta autora aprofunda mais sobre o tema, confirmando que a Percussão, quando executada de forma correta gera um efeito localizado ou sistêmico. Quando de forma leve: há melhor resposta do sistema nervoso e do nervo sensitivo, além da tonificação dos músculos. Quando os movimentos são intensificados: há insensibilidade parcial, liberação de mucosidades, liberação miofascial, cresce a frequência do fluxo sanguíneo no local, e também são liberadas substâncias que produzem o hormônio do prazer (PEREZ et al., 2012, p.105-106). 


\section{Vibrações}

De efeito relaxante, o movimento de tremer as mãos sobre determinado local da pele lhe repassa esta vibração. Podem ser utilizados vibradores mecânicos já que os mesmos possuem uma vibração mais precisa (GONÇALVES, 2006, p.133).

\section{Beliscamentos}

Como o próprio nome já diz, esta manobra consiste em pequenos beliscões com o polegar e o indicador ou o médio, em todo corpo. Por serem movimentos estimulantes, atuam diretamente na circulação sanguínea (GONÇALVES, 2006, p.133).

\section{Leque}

É um movimento de imitar com as mãos o abrir e fechar de um leque. Tem por objetivo relaxar os músculos e auxiliar no esvaziamento das toxinas (GONÇALVES, 2006, p.134).

Falando do processo da resposta inflamatória do corpo, este autor exemplifica como ela ocorre: Quando o corpo sofre qualquer tipo de dano como uma queimadura, cirurgia ou uma agressão muito profunda na pele, ele corresponde a este processo inflamatório através de respostas bioquímicas de células especificas, formando a cicatriz e evitando assim uma infecção. Este mecanismo tem ação imediata após a lesão, os macrófagos (que são células específicas do sistema imunológico), se migram rapidamente para o local combatendo o agente infeccioso. Mesmo com toda sua eficácia, no processo de cicatrização também envolve a nova formação de fibras de colágeno e esta ação é desordenada, pois os fibroblastos estendem se para fechar a lesão. Neste processo acontece primeiramente a inflamação e hipermia do local seguido da ativação do tecido granular, dos fibroblastos e de novos tecidos, da contratura do ferimento, da formação de novos vasos sanguíneos, da neoformação do colágeno e restauração da pele. E ressalta que, é nesta ultima etapa onde o massoterapeuta irá trabalhar, visto que a manipulação do tecido conjuntivo denso irá provocar respostas significativas neste quadro (VERSAGI, 2015, p.259-260).

Um estudo científico realizado com 11 atletas voluntários nos Estados Unidos da América (EUA) e que foi recentemente publicado na revista Science Translational Medicine, afirmou que a massagem tem poder anti-inflamatório e é eficiente na cicatrização do tecido muscular lesionado. Sendo assim, os cientistas determinaram que este procedimento atua na geração de sinais químicos neurotransmissores que reduzem o processo inflamatório e excita 
as mitocôndrias (estruturas celulares responsáveis pela respiração celular), atuando também na recuperação da dor localizada e persistente em músculos, tendões, ligamentos, articulações e ossos de qualquer área corporal, beneficiando indivíduos idosos ou que sofreram lesões traumáticas profundas e também com doença inflamatória crônica, a pesquisa também afirma que mesmo apesar de a massagem não inibir os metabólitos musculares, o seu poder antiinflamatório, diminui o estresse muscular (CRANE et.al.2012).

Este estudo confirmou sobre o processo da Metanálise, que se baseia em reunir todas as informações das pesquisas realizadas em pacientes com determinada condição e ser aplicada a mesma terapia ou procedimentos semelhantes. E salienta que os melhores resultados são obtidos com uma população maior de estudo, e se estes mesmos forem iguais para diferentes grupos de amostra, a probabilidade do efeito de intervenção é maior. Afirma ainda que esta análise pode ser feita em toda a população, de crianças a idosos e de diferentes patologias. Fazendo-o ser reconhecido externamente e instigando outros a realizar novos estudos sobre o tema (BRASIL, 2012, p.14).

A idade do paciente, seu metabolismo, o uso de vitaminas, a secreção da Insulina, o sistema imunológico em pleno funcionamento e até sua etnia influenciam diretamente na recuperação do tecido lesionado (VERSAGI, 2015, p.260).

\section{Indicações}

A massagem não é indicada somente para o relaxamento muscular ainda que ela atue no sistema nervoso autônomo, mas também na eliminação das toxinas, pois seus movimentos estimulam o sistema venoso e linfático. E em outros casos age em determinadas condições patológicas, quando esta é indicada por um médico (CASSAR, 2001, p.162).

\section{Contra-indicações}

Ainda que a massagem ofereça muitos benefícios não se deve afastar a hipótese de uma contra indicação, para isso a primeira observação a ser feita é a de afastar a possibilidade de uma patologia ser agravada pela massagem. Embora geralmente a região danificada seja isolada 
e se dê continuidade ao procedimento, este ato exige do profissional conhecimento em anatomia e patologia e se precisar contactar um médico, a ficha de anamnese é imprescindível neste momento (CASSAR, 2001, p.163).

Sendo assim podemos concluir que, a massagem no tecido muscular tem a finalidade de prover as células através do sangue, promover a organização das atividades do tecido conjuntivo e dos fibroblastos além de ter propriedades anti-inflamatórias (DONATELLI, 2015).

\section{Considerações Finais}

Partindo do principal objetivo deste artigo, no qual foi sistematizar com base na literatura científica sobre o referido tema, confrontando diversos autores e comprovando-o por meio do processo de Metanálise. Obteve-se como resultado desta proposta realizada através de estudos recentes que a massoterapia pode influenciar diretamente no sistema imunitário, uma vez que suas manobras agem profundamente nas camadas da pele, e ela responde positivamente, já que quando o imunológico de um indivíduo está fortalecido, o mesmo apresenta melhor qualidade de vida.

\section{Referências}

BRASIl, MINISTÉRIO DA SAÚDE. Elaboração de revisão sistemática e metanálise de ensaios clínicos randomizados: Departamento de Ciência e Tecnologia - Brasília: 2012. Disponível em: http://bvsms.saude.gov.br/bvs/publicacoes/diretrizes_metodologicas_ elaboracao_sistematica.pdf. Acesso: 06/01/17.

CARDIM, V. Massagem Ayurvédica: Ciência da Vitalidade. Lisboa: Dinalivro, 2012.

CASSAR, M. P. Manual de Massagem Terapêutica. $1^{\circ}$ ed. São Paulo: Editora Manole, 2001.

CRANE, J. D.; OGBORN, D. I.; CUPIDO, C.; MELOV, S.; HUBBARD, A. et al. Massage therapy attenuates inflammatory signaling after exercise-induced muscle damage. Sci. Transl. Med. v. 4, n. 119, p. 119ra13, 2012.

DONATELLI, Sidney. A linguagem do toque: massoterapia oriental e ocidental. $1^{\circ}$. Ed. - Rio de Janeiro: Roca, 2015. 
GONÇALVES, Águeda. Manual Técnico de Estética: Teoria e prática para Estética, Cosmetologia e Massagem. Impressão: Ondagrafe - $2^{\circ}$ Ed. Setembro/ 2006.

LAD, V. Ayurveda: a ciência da auto cura: Guia Prático. São Paulo: Ground, 2012

PEREIRA, Maria de Fátima Lima. Recursos Técnicos em Estética. Vol. I. Série Curso de Estética. São Paulo. Difusão Editora. 2013.

PEREZ, Erika; LEVIN, Raquel. Técnicas de massagens ocidental e oriental. $1^{\circ}$. ed.- São Paulo: Érica, 2014..

VERSAGI, Charlotte Michael. Protocolos terapêuticos de massoterapia: técnicas passo a passo para diversas condições clínicas / Charlotte Michael Versagi ; [tradução Douglas Arthur Omena Futuro]. -- 1. ed. -- Barueri, SP : Manole, 2015.

\section{Como citar este artigo (Formato ABNT):}

CARVALHO, Rosemeire de Jesus; ALMEIDA, Maria A.P.T. Efeitos da Massoterapia Sobre o Sistema Imunológico. Id on Line Rev.Mult. Psic., 2018, vol.12, n.40, p.353-366. ISSN: 1981-1179.

Recebido: 01/04/2018

Aceito 05/04/2018 